\title{
Spectral and Thermal Degradation of Melamine Cyanurate
}

\author{
V. Sangeetha, ${ }^{1}$ N. Kanagathara, ${ }^{2}$ R. Sumathi, ${ }^{3}$ N. Sivakumar, ${ }^{4}$ and G. Anbalagan ${ }^{4}$ \\ ${ }^{1}$ Department of Physics, D.G. Vaishnav College, Arumbakkam, Chennai 106, India \\ ${ }^{2}$ Department of Physics, Vel Tech Multi Tech Dr. Rangarajan Dr. Sakunthala Engineering College, Avadi, Chennai 62, India \\ ${ }^{3}$ Department of Physics, Vel Tech Polytechnic College, Avadi, Chennai 62, India \\ ${ }^{4}$ Department of Physics, Presidency College, Chennai 5, India
}

Correspondence should be addressed to G. Anbalagan; anbu24663@yahoo.co.in

Received 14 December 2012; Accepted 25 January 2013

Academic Editor: Carmen Alvarez-Lorenzo

Copyright (C) 2013 V. Sangeetha et al. This is an open access article distributed under the Creative Commons Attribution License, which permits unrestricted use, distribution, and reproduction in any medium, provided the original work is properly cited.

\begin{abstract}
Melamine cyanurate, an organic crystalline complex was, synthesized by evaporation of an aqueous solution containing equimolar quantities of melamine and cyanuric acid. The synthesized compound has been subjected to various characterizations like Powder XRD, FT-IR, TG-DTG, SEM, and SHG. The presence of sharp diffraction peaks in the XRD confirms that the products are highly crystalline. The average particle size was calculated using the Debye-Scherrer formula, and it was found to be $3.067 \mu \mathrm{m}$. Thermal behavior of the grown crystal has been studied by TG-DTG analysis. From TG-DTG, it is found that the title crystal possesses good thermal stability. The activation energy was calculated using the Broido, Coats-Redfern, and Horowitz-Metzger methods. A sharp peak exothermic peak at $405.40^{\circ} \mathrm{C}$ was assigned as the melting point of the title material. SEM reveals the morphology of the synthesized salt. No detectable signal was observed during the Kurtz-Perry technique.
\end{abstract}

\section{Introduction}

The rapid growth in material and processing technology makes it essential for its use in various industrial applications. Cyanuric acid which is also known as triazinetriol or trihydroxy cyaniding is a polymer of cyanic acid and arises by dry heating of urea. The organic derivatives of cyanuric acid find wide industrial applications today. The composition of cyanurates includes the s-triazine ring formed as a result of trimerization of the cyanato groups. The cyanuric acid derivatives containing the s-triazine ring $\left(\mathrm{C}_{3} \mathrm{~N}_{3}\right)$ are considered to be promising compounds for the synthesis of complexes [1]. The strong interaction of the $\pi$ electrons of the cyanuric acid with the unshared electron pair of the amine nitrogen atom imparts basic properties to the melamine amino groups. Two forms of hydrogen bonding between melamine and cyanuric acid are suggested with a planar structure $[2,3]$. Flame retardancy is one of the important properties in industrial application. Melamine cyanurate offers better thermal stability (up to $377^{\circ} \mathrm{C}$ ) than pure melamine. This helps in polymer processing steps. Both melamine and cyanuric acid have got several industrial applications [4]. Melamine cyanurate is particularly effective in improving fire safety of nitrogen-based polymers, such as polyamides (nylons) and thermoplastics (polyurethane). It can be used in epoxy polymers and in a variety of other substrates. These complexes are very promising light-emitting materials because of their good thermal stability [5]. The thermochemical properties of cyanuric acid were characterized using mass spectrometry measurements along with computational studies was already reported by Mukherjee and Ren [6]. Cyanuric acid is a triazine derivative and may also be described as two structural isomers, the enol-like triazine-triol and the keto-like tautomer. Cyanuric acid is commonly used as a component of bleaches in swimming pools $[7,8]$. Cyanuric acid can form hydrogen bonded self-assemblies with specific surface structures, and these assemblies have been used as surface templates in supramolecular chemistry [9]. Cyanuric acid is used in the preparation of high performance magnet-wire enamels and in electrical varnishes, plastics with enhanced properties, flame retardant resins and solid lubricants, and cross-linking and curing agents in the manufacture plastics and coatings. Cyanuric acid is also used to reduce nitrogen oxides (NOX) in stationary diesel engine exhaust gases. In 
the present work, melamine cyanurate has been synthesized and characterized by subjecting it to various studies like XRD, FT-IR, and TG-DTG, and results are discussed in detail.

Cyanuric acid is mainly used as a precursor to $\mathrm{N}$ chlorinated cyanurates, which are used to disinfect water. Cyanuric acid is also used in the manufacture of specialty intermediates used in the production of plastics and coatings. This paper discusses the structure, properties, analysis, chemistry, manufacture, and uses of cyanuric acid.

$$
(\mathrm{HNCO})_{3}+\left(\mathrm{H}_{2} \mathrm{NCN}\right)_{3} \longrightarrow(\mathrm{HNCO})_{3} \cdot\left(\mathrm{H}_{2} \mathrm{NCN}\right)_{3}
$$

cyanuric acid + melamine $\longrightarrow$ melamine cyanurate

Cyanuric acid (1,3,5-triazine-2,4,6-triol) is the cyclic trimer of cyanic acid [10]. It is an organic compound with the chemical formula $\mathrm{C}_{3} \mathrm{H}_{3} \mathrm{~N}_{3} \mathrm{O}_{3}$. It has wide industrial applications. This triazine derivative is a stable, white, odorless, and hygroscopic solid at room temperature. It is used as a stabilizer in recreational water treatment to minimize the decomposition of hypochlorous acid by light in outdoor swimming pools and hot tubs. Chlorinated derivatives of cyanuric acid, such as trichloro-s-triazinetrione and sodium dichloro-s-triazinetrione, are used as algacides or microbiocides in swimming pool water and large-scale water systems in industry [11]. The ring in its molecule has an aromatic character, and the hydroxyl groups in the triol form of the molecule take on a phenolic character, becoming somewhat more acidic than hydroxyls in an alcohol. The hydrogen of any one of cyanuric acid hydroxyls can be neutralized to form a cyanurate salt [12]. Melamine cyanurate is a halogen-free flame retardant that can be used in thermoplastic urethanes (TPUs) for electrical wire coatings [13-15].

\section{Materials and Methods}

AR grade samples of melamine and cyanuric acid were taken in 1:1 ratio, and the hot solution of cyanuric acid was added dropwise to the hot solution of melamine. The mixed solution was stirred well for nearly 4 hours and then allowed to cool at room temperature. During a few days, the entire solvent was evaporated and the white colour melamine cyanurate was obtained which are insoluble in water and common organic solvents like acetone, chloroform, benzene, alcohol, and so forth but soluble in strong acids or basic solutions [16]. The obtained compound was then washed with distilled water to remove the presence of impurities and dried at a constant temperature of $80^{\circ} \mathrm{C}$.

\section{Characterization}

The synthesized compound has been subjected to various characterization studies like Powder XRD, FT-IR, TG-DTG, SEM, and SHG. The synthesized compound has been characterized by X-ray powder diffraction technique using Rich Seifert X-ray powder diffractometer with $\mathrm{CuK} \alpha$ radiation of $\lambda=1.5406 \AA$. The $2 \theta$ range was analyzed from $10^{\circ}$ to $70^{\circ}$ by employing the reflection mode for scanning. The detector used was a scintillation counter. A Perkin Elmer

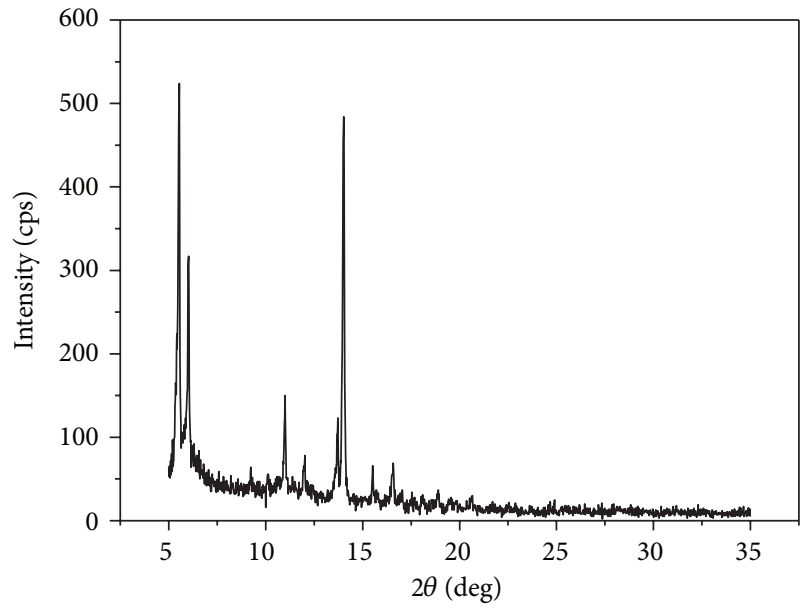

Figure 1: Powder X-ray diffraction pattern of melamine cyanurate complex.

Spectrum ONE FT-IR spectrometer was employed to record the IR spectrum to analyze the functional groups present in the synthesized melamine cyanurate compound. The sample for this measurement was finely grounded and mixed with $\mathrm{KBr}$. TG-DTG spectra were recorded for the synthesized melamine cyanurate compound using SDT Q $600 \mathrm{~V} 8.0$ build 95 thermal analyzer with a heating rate of $20^{\circ} \mathrm{C} / \mathrm{min}$ in the temperature up to $1000^{\circ} \mathrm{C}$ in nitrogen atmosphere. The Quanta 200 FEG scanning electron microscope (SEM) was used to know the surface morphology of the synthesized salt with a resolution of $1.2 \mathrm{~nm}$ gold particle separation on a carbon substrate with a magnification from a minimum of $12 \mathrm{X}$ to greater than $1,00,000 \mathrm{X}$. The nonlinear optical activity of melamine cyanurate was identified by illuminating it with an Nd:YAG laser. In this technique, sample packed in a cell was sandwiched between two glass plates and was subjected to the output of a $\mathrm{Q}$ switched Nd:YAG laser emitting a functional $\lambda$ of $1064 \mathrm{~nm}$ with $10 \mathrm{~ns}$ pulse width with a power output $20 \mathrm{~mW}$.

\section{Results and Discussion}

4.1. Powder X-Ray Diffraction Analysis. Figure 1 shows the powder XRD pattern of melamine cyanurate. The presence of sharp diffraction peaks in the XRD confirms that the products are highly crystalline. The average grain size $(D)$ of the synthesized was calculated by the Debye-Scherrer formula, $D=0.9 \lambda / \beta \cos \theta$, where $\lambda$ is the wavelength of $\mathrm{CuK} \alpha$ line $(\lambda=1.5418 \AA), \beta$ is the full width at half maximum height, and $\theta$ is the diffraction angle. From the XRD analysis, the average particle size of the title material was estimated as $3.067 \mu \mathrm{m}$.

4.2. FT-IR Studies. Figure 2 shows the FT-IR spectrum of melamine cyanurate, and the vibration band assignment is listed in the Table 1. Internal vibrations of melamine molecule were recently published $[17,18]$. According to crystallographic data, melaminium residues often form hydrogen 
TABLE 1: Vibration band assignment of melamine cyanurate.

\begin{tabular}{|c|c|c|}
\hline Observed wavenumber $\left(\mathrm{cm}^{-1}\right)$ & Assignment & References \\
\hline 3396 & $\mathrm{NH}_{2}$ symmetric stretching type of vibrations of 3 triazine $\mathrm{NH}_{2}$ groups & [3] \\
\hline 3234 & $\mathrm{~N}-\mathrm{H}$ symmetric stretching & {$[4]$} \\
\hline 3041 & $\mathrm{~N}-\mathrm{H} \cdots \mathrm{N}$ stretching & {$[8]$} \\
\hline 2825 & $\mathrm{~N}-\mathrm{H}$ deformation (cyanuric acid) & {$[12]$} \\
\hline 2698 & $\mathrm{NH}_{2}$ asymmetric stretching & {$[10]$} \\
\hline 1782 & Stretching vibration of the carbonyl group $\mathrm{C}=\mathrm{O}$ & {$[2]$} \\
\hline 1743 & $\mathrm{NH}_{2}$ scissoring & {$[9]$} \\
\hline 1667 & $\mathrm{NH}_{2}$ bending vibration & {$[4]$} \\
\hline 1528 & $\mathrm{C}=\mathrm{N}$ symmetric stretching & {$[2]$} \\
\hline 1449 & $\mathrm{C}-\mathrm{N}$ symmetric stretching & {$[2]$} \\
\hline 1036 & Ring breathing type of vibration & [11] \\
\hline 924 & Ring breathing type of vibration & [13] \\
\hline 808 & Ring-sextant out-of-plane bending type of vibration & {$[9]$} \\
\hline 771 & Ring-sextant out-of-plane bending type of vibration & {$[9]$} \\
\hline 596 & Ring bending vibration & [11] \\
\hline 529 & Side chain in plane $\mathrm{C}-\mathrm{N}$ bending vibration & {$[12]$} \\
\hline
\end{tabular}

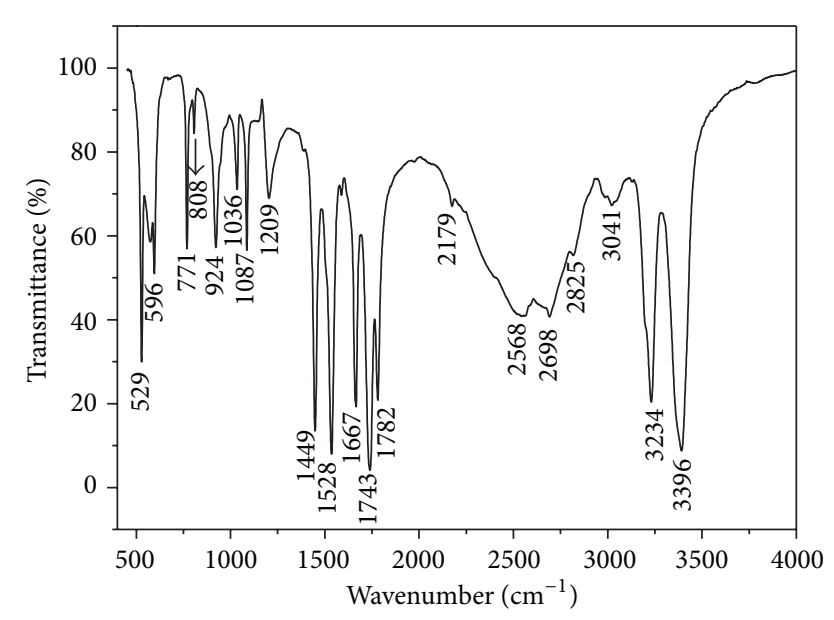

FIGURE 2: FT-IR spectrum of melamine cyanurate.

bonds of $\mathrm{N}-\mathrm{H} \cdots \mathrm{N}$ and $\mathrm{N}-\mathrm{H} \cdots \mathrm{O}$ type. Melamine cyanurate complex is held together by an extensive two-dimensional network of hydrogen bonds between the two compounds. The bands observed in the measured region $4000-350 \mathrm{~cm}^{-1}$ arise from internal vibrations of melaminium cations, cyanuric acid anions and water molecules, the vibrations of both $\mathrm{N}-$ $\mathrm{H} \cdots \mathrm{O}$ and $\mathrm{O}-\mathrm{H} \cdots \mathrm{O}$ types of hydrogen bond, and from the vibrations of lattice. The three amino groups in the melamine molecule have different types of hydrogen bonds. The melamine molecules are not linked by hydrogen bonds to each other. Due to this system of hydrogen bond network, the visible modes of $\mathrm{NH}_{2}, \mathrm{OH}$ and the six-membered ring of melamine are expected to give unusual frequencies and intensities for the IR bands [19]. A strong peak at $3396 \mathrm{~cm}^{-1}$ is due to the $\mathrm{NH}_{2}$ symmetric stretching type of vibrations of triazine groups [3], and this band usually occurs at $3328 \mathrm{~cm}^{-1}$ in melamine crystal [20]. The difference of $68 \mathrm{~cm}^{-1}$ is known as blue shift. Similar shift is observed in Debrus et al. [21]. The strong intense peak at $3234 \mathrm{~cm}^{-1}$ and medium peak at $3041 \mathrm{~cm}^{-1}$ are due to the formations of hydrogen bonding between $\mathrm{NH}_{2} / \mathrm{NH}$ groups. $\mathrm{N}-\mathrm{H}$ stretching vibration occurs at $3205 \mathrm{~cm}^{-1}$ and $3079 \mathrm{~cm}^{-1}$ which shifted to lower wave numbers compared with those of melamine $[5,12]$. The medium peak at $2825 \mathrm{~cm}^{-1}$ is assigned to $\mathrm{N}-\mathrm{H}$ deformation. Usually this band appears in the range of $2828 \mathrm{~cm}^{-1}-$ $2907 \mathrm{~cm}^{-1}$ in the cyanuric acid spectrum [22]. A medium peak at $2698 \mathrm{~cm}^{-1}$ can be assigned to $\mathrm{NH}_{2}$ asymmetric stretching of vibration [19]. The stretching vibration of the carbonyl group $\mathrm{C}=\mathrm{O}$ at $1782 \mathrm{~cm}^{-1}$ is due to cyanate anion [4]. The strong peak at $1743 \mathrm{~cm}^{-1}$ is assigned to $\mathrm{NH}_{2}$ scissoring [18]. Several pronounced differences have been observed between the IR spectrum of melamine crystal and that for melamine cyanurate in region of $\mathrm{NH}_{2}$ bending type of vibration. A weak band appears at $1667 \mathrm{~cm}^{-1}$, and this occurs usually at higher frequencies $\left(1666 \mathrm{~cm}^{-1}\right)$. This may be due to intermolecular interaction through the $\mathrm{NH}_{2}$ groups of melamine molecule. This causes the rising of their frequencies for bending type of motion [22]. The triple bond $\mathrm{C}-\mathrm{N}$ stretching frequency in the IR spectra of cyanurates should be assigned to a strong polarization of the cyanurate anion by melamine cation [4]. The benzene ring has two intense absorption bands corresponding to the vibrations of $\mathrm{C}-\mathrm{N}$ and $\mathrm{C}=\mathrm{N}$ bonds. This appears in the region of $1450 \mathrm{~cm}^{-1}-1500 \mathrm{~cm}^{-1}$ and $1530 \mathrm{~cm}^{-1}-1600 \mathrm{~cm}^{-1}$, respectively which indicates the presence of cyanuric acid. Similar bands are shifted to lower frequency of $1449 \mathrm{~cm}^{-1}$ and $1528 \mathrm{~cm}^{-1}$ in our spectra [4]. The band corresponds to $\mathrm{C}=\mathrm{N}$ stretching frequency vibration occurs in the range of $1590 \mathrm{~cm}^{-1}$ $1600 \mathrm{~cm}^{-1}$. Which may either be appearing weak or disappear. The medium band at $1036 \mathrm{~cm}^{-1}$ [20] and $924 \mathrm{~cm}^{-1}$ originates from ring breathing type of vibration. And the peaks at 


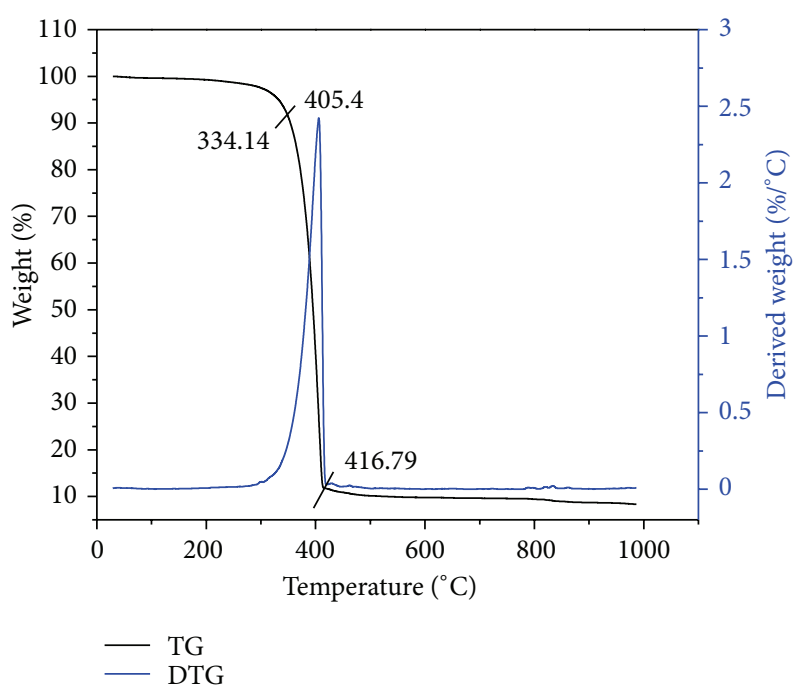

FIGURE 3: TG-DTG spectrum of melamine cyanurate.

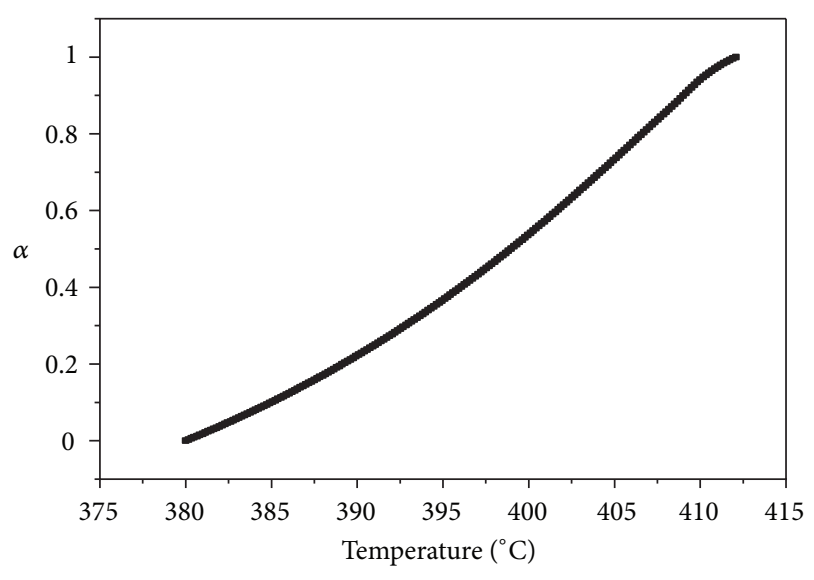

FIGURE 4: Fraction reacted $\alpha$ versus temperature.

$808 \mathrm{~cm}^{-1}$ and $771 \mathrm{~cm}^{-1}$ are attributed to ring-sextant out-ofplane bending type of vibration [18], and the medium peak at $596 \mathrm{~cm}^{-1}$ is due to ring bending [20], and the peak at $529 \mathrm{~cm}^{-1}$ is due to the side chain in plane $\mathrm{C}-\mathrm{N}$ bending vibration [22].

4.3. Thermogravimetric Analysis. Figure 3 shows the TGDTG spectra recorded for the synthesized melamine cyanurate. The TG curve exhibits mass losses in a single stage which indicates that decomposition of the grown crystals takes place sharply. Initial mass is taken as $3.0210 \mathrm{mg}$. The thermal decomposition of melamine cyanurate is accompanied by the detachment of ammonia and gradual linking of cyanuric rings through imide bridges [4]. The initial weight loss starts at $334.14^{\circ} \mathrm{C}$ and ends at $416.79^{\circ} \mathrm{C}$ with about $88.25 \%$ of weight loss which corresponds to liberation of ammonia and water molecules followed by the decomposition of cyanuric acid to volatile cyanates. There is a sharp weight loss which is indicated by the derivative curve as peak. This suggest that there is no other processes of decomposition except transition from solid to liquid state which is designated as melting point,

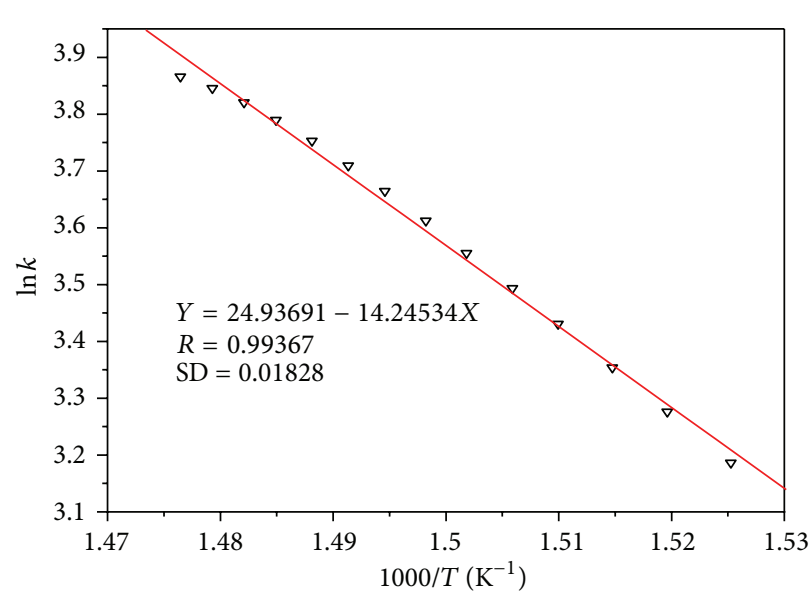

Figure 5: The Arrhenius plot.

and this occurs at $405.4^{\circ} \mathrm{C}$ as indicated in Figure 3. For pure melamine this occurs at $354^{\circ} \mathrm{C}$ [4]. Thus it can be understood that melamine cyanurate offers better thermal stability than pure melamine (up to $320^{\circ} \mathrm{C}$ ). This enables its use in polymers for processing. The decomposition at $407^{\circ} \mathrm{C}$ may be due to decay of cyanates. The thermal decomposition of melamine cyanurate may be decomposition of melamine and cyanuric acid. Above $250^{\circ} \mathrm{C}$, carbonyl groups are replaced with amine groups in cyanuric acid. The decomposition ends with a final residue of $0.2513 \mathrm{mg}$.

Various researchers put forward integral method, which can be applied to TG data assuming order of reaction and from which the activation energy is calculated. Generally, mass conversion can be calculates as

$$
\alpha=\frac{m_{o}-m}{m_{o}-m_{f}},
$$

where $m_{o}$ is the initial mass, $m$ is the corresponding mass, and $m_{f}$ is the final mass.

Kinetic studies assumed that the isothermal rate of conversion, $d \alpha / d t$, is a linear function of reactant concentration loss and of temperature-independent function of the conversion $\alpha$ :

$$
\frac{d \alpha}{d t}=k f(\alpha)
$$

where $f(\alpha)$ is reaction model that depends on the mechanism of degradation. The function $k$ is described by the Arrhenius expression

$$
\begin{aligned}
& k=A \exp \left(-\frac{E_{a}}{R T}\right), \\
& \ln k=\ln A-\frac{E_{a}}{R T},
\end{aligned}
$$

where $A$ is preexponential factor independent of temperature, $E_{a}$ is activation energy, and $R$ is the universal gas constant.

The linear Arrhenius plot of $\ln k$ versus $1 / T$ is plotted from the TG data. From the slope $\left(-E_{a} / R\right)$, the activation energy $\left(E_{a}\right)$ was calculated. 


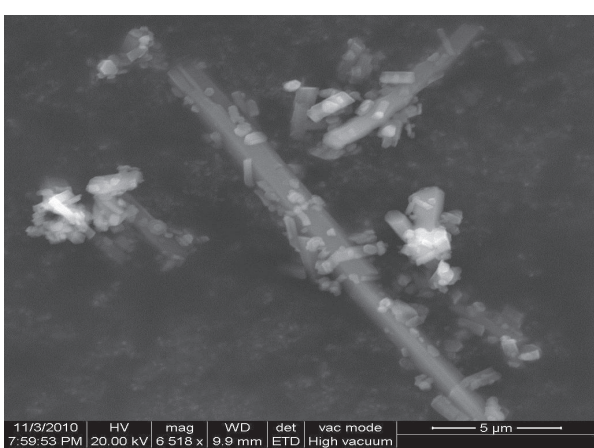

(a)

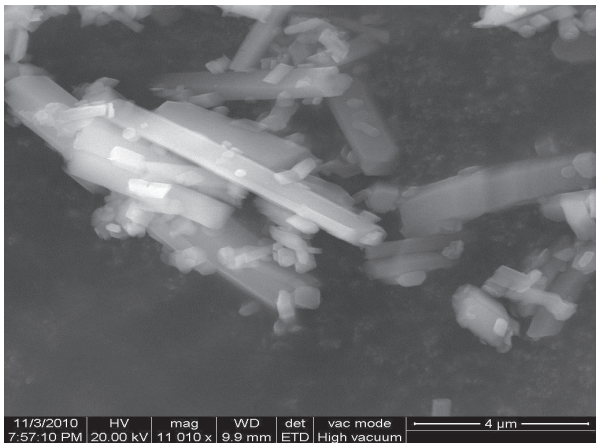

(c)

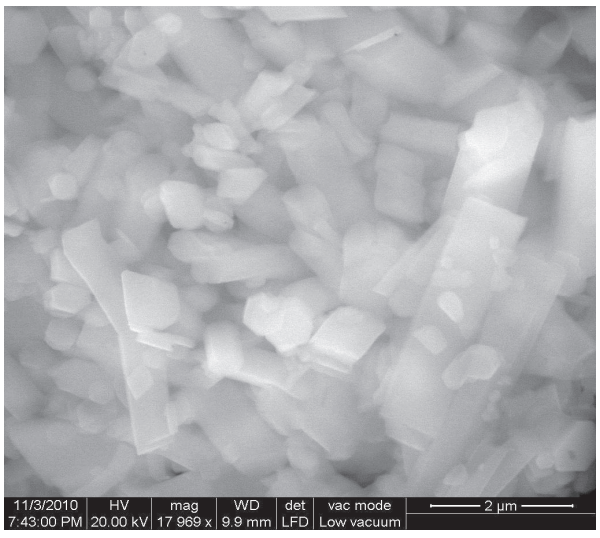

(e)

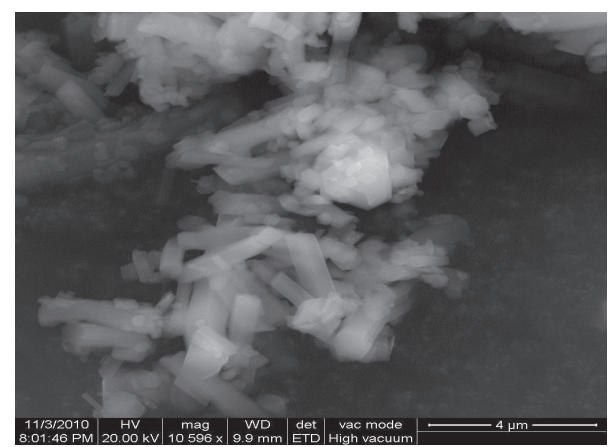

(b)

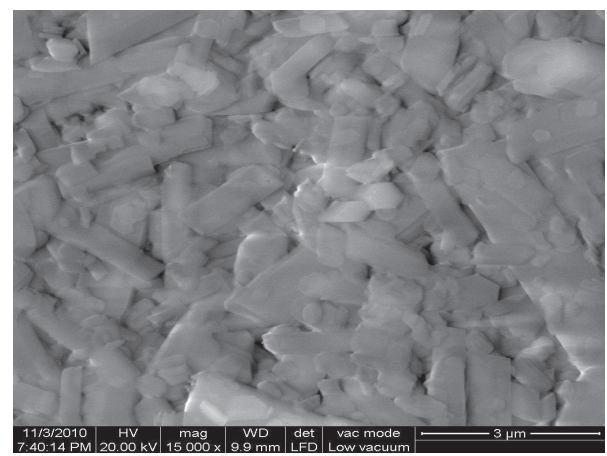

(d)

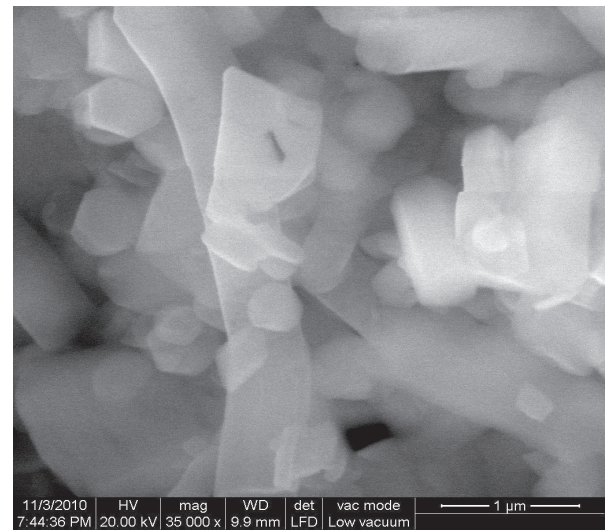

(f)

FIGURE 6: (a) SEM photograph with 6518X, (b) SEM photograph with 10500X, (c) SEM photograph with 11010X, (d) SEM photograph with 15000X, (e) SEM photograph with 17900X, and (f) SEM photograph with 35000X.

Equation (3) can be writtens as

$$
\frac{d \alpha}{d t}=\beta\left(\frac{d \alpha}{d T}\right)=A f(\alpha) \exp \left(-\frac{E_{a}}{R T}\right)
$$

where $\beta$ is the heating rate $\left(20^{\circ} \mathrm{C} / \mathrm{min}\right)$ and $f(\alpha)$ is the reaction model.

Figure 4 shows the fraction reacted $\alpha$ versus temperature. The Arrhenius plot is shown in Figure 5.
4.3.1. Broido's Method. Consider,

$$
\ln \left[\ln \left(\frac{1}{\alpha}\right)\right]=\left(-\frac{E_{a}}{R T}\right)+\left[\frac{R A T^{2}}{E_{a} \beta}\right] .
$$

In Broido's approximation [23], the thermal degradation is considered as first-order and the calculations are done accordingly. The value of the activation energy $\left(E_{a}\right)$ can be calculated from the slope of the plot of graph between $\ln [\ln (1 / y)]$ and $1 / T$. The calculated activation energy is $325.21 \mathrm{KJ} \mathrm{mol}^{-1}$. 
TABLE 2: Kinetic parameters obtained by different methods.

\begin{tabular}{lccc}
\hline Method & Activation energy $\left(\mathrm{kJ} \mathrm{mol}^{-1}\right)$ & $R$ & S.D \\
\hline Arrhenius & 118.44 & 0.99367 & 0.01828 \\
Broido & 325.21 & 0.9964 & 0.03063 \\
Coats-Redfern & 393.33 & 0.99939 & 0.00598 \\
Horowitz-Metzger & 336.57 & 0.98575 & 0.03021 \\
\hline
\end{tabular}

\subsubsection{The Coats-Redfern Method. Consider,}

$\ln \left[-\frac{\ln (1-\alpha)}{T^{2}}\right]=\ln \left(\frac{A R}{\beta E_{a}}\right)\left[1-\frac{2 R T}{E_{a}}\right]-\frac{E_{a}}{R T} \quad$ for $n=1$.

By using the Coats-Redfern expression [24], the value of the activation energy $\left(E_{a}\right)$ can be calculated from the slope of the plot of graph between $\ln \left[-\ln (1-\alpha) / T^{2}\right]$ and $1 / T$. The calculated activation energy is $393.33 \mathrm{KJ} \mathrm{mol}^{-1}$.

\subsubsection{The Horowitz-Metzger Method [25]. Consider,}

$$
\ln (1-\alpha)=\frac{E_{a}\left(T-T_{p}\right)}{R T_{p}} \text { for } n=1
$$

By using the expression above (9), the activation energy $\left(E_{a}\right)$ can be calculated from the slope of the plot of graph between $\ln (1-\alpha)$ and $1 / T$. The calculated activation energy is $336.57 \mathrm{KJ} \mathrm{mol}^{-1}$. The activation energy $\left(E_{a}\right)$ and preexponential factor $(A)$ calculated from all the above methods were listed in Table 2.

4.4. Scanning Electron Microscope Analysis. Scanning electron microscopy was used to study the surface features of the synthesized salt. Figures 6(a)-6(f) shows different types of morphologies exhibited by synthesized salt at different magnifications. The various types of morphologies include spherulites, platelets, cuboids, and coalesced and rod-shaped crystals. It is seen from SEM observation that the decomposition takes place starting from a relevant number of nuclei which grow rapidly enough. Melamine cyanurate forms spoke-like crystals in aqueous solutions. Figures 6(a)-6(f), shows the SEM photograph of melamine cyanurate under different magnifications with $1-5 \mu \mathrm{m}$ in size.

4.5. Kurtz Perry Technique. The sample was found to be NLO inactive. There is no emission of green $(\lambda=520 \mathrm{~nm})$ radiation which confirms that there is no production of second harmonic generation.

\section{Conclusion}

Melamine cyanurates were obtained by employing slow evaporation solution growth technique. The grown crystals are of $1 \mu \mathrm{m}$ to $5 \mu \mathrm{m}$ size. The Powder XRD pattern of the complex ensures its crystallinity. The FTIR spectrum clearly indicates the presence of functional groups in the complex. The TGDTG studies were used to formulate the decomposition pattern of the complex compound, and it is found that thermal stability for melamine cyanurate is more than that of pure melamine and hence finds applications in polymers for processing at high temperatures. From the Arrhenius expression, a linear straight line equation is obtained. Activation energy was calculated by four different methods the Arrhenius, Broido, Coats-Redfern, and Horowitz-Metzger methods. Among four different methods, activation energy obtained by Coats-Redfern is higher. And activation energy obtained by Arrhenius method $E_{a}$ is $118.4 \mathrm{~kJ} / \mathrm{mol}$ which is much lower than that obtained from other methods. This is so because the data are taken at a single heating rate $\left(20^{\circ} \mathrm{C} / \mathrm{min}\right)$ in all the cases which may not be applicable. This is more so if mechanism of decomposition is going to change, and this will be confirmed at different heating rates like 5, 10 and $15^{\circ} \mathrm{C} / \mathrm{min}$. Also these complexes are very promising lightemitting materials due to their good thermal stability. There is no emission of green signal through Kurtz-Perry technique which confirms that the synthesized material is not having second harmonic generation efficiency. Further research has to be carried out and can be extended to several industrial and research applications.

\section{References}

[1] H. Zhu, Z. Yu, X. You, H. Hu, and X. Huang, "The crystal and molecular structure of bis(melamine)silver(I) perchlorate, $\mathrm{Ag}\left(\mathrm{C}_{3} \mathrm{H}_{6} \mathrm{~N}_{6}\right)_{2} \mathrm{ClO}_{4}$," Journal of Chemical Crystallography, vol. 29, no. 2, pp. 239-242, 1999.

[2] Y. Wang, B. Wei, and Q. Wang, "Crystal structure of melamine cyanuric acid complex (1:1) trihydrochloride, MCA.3HCl," Journal of Crystallographic and Spectroscopic Research, vol. 20, no. 1, pp. 79-84, 1990.

[3] F. H. Herbstein, "Purported "melamine cyanuric acid trihydrochloride" $\mathrm{C}_{3} \mathrm{H}_{6} \mathrm{~N}_{6} \cdot \mathrm{C}_{3} \mathrm{H}_{3} \mathrm{~N}_{3} \mathrm{O}_{3} \cdot 3 \mathrm{HCl}$ is actually "diprotonatedmelamine cyanuric acid dichloride dihydrate" $\left(\mathrm{C}_{3} \mathrm{H}_{8} \mathrm{~N}_{6}\right) 2+$ . $\mathrm{C}_{3} \mathrm{H}_{3} \mathrm{~N}_{3} \mathrm{O}_{3} \cdot 2 \mathrm{Cl}-2 \mathrm{H}_{2} \mathrm{O}$," Journal of Chemical Crystallography, vol. 33, no. 7, pp. 527-529, 2003.

[4] G. R. Seifer, "Cyanuric acid and cyanurates," Russian Journal of Coordination Chemistry, vol. 28, no. 5, pp. 301-324, 2002.

[5] Y. Qiu and L. Gao, "Blue-emitting cyanuric acid-melamine complexes from urea thermolysis," Materials Research Bulletin, vol. 40, no. 5, pp. 794-799, 2005.

[6] S. Mukherjee and J. Ren, "Gas-Phase acid-base properties of melamine and cyanuric acid," Journal of the American Society for Mass Spectrometry, vol. 21, no. 10, pp. 1720-1729, 2010.

[7] A. Zaknich, "Swimming pool and Spa water testing process," Granted innovation Pat. (Australia). Application, AU 2009100474, 8, 2009.

[8] V. I. Teichberg, "Methods and compositions and Devices for maintaining chemical balance of chlorinated water," Yeda Research and Development co.Ltd., Israel, In PCT Int. Appl; Application, WO 2007107981, 58, 2007.

[9] K. Damodaran, G. J. Sanjayan, P. R. Rajamohanan, S. Ganapathy, and K. N. Ganesh, "Solid state NMR of a molecular self-assembly: multinuclear approach to the cyanuric acidmelamine system," Organic Letters, vol. 3, no. 12, pp. 1921-1924, 2001.

[10] N. Kriebizsch, N. V. Degussa-Antwerpen, H. Klenk, and W. H. Degussa, in Ullmann's Encyclopedia of Industrial Chemistry, 
W. Gerhartz, Y. S. Yamamoto, L. Kaudy, R. Pfefferkorn, and F. Rounsavaille, Eds., vol. 8, p. 191, Wiley, New York, NY, USA, 5th edition, 1987.

[11] G. Herzberg and C. I. Reid, "Infra-red spectrum and structure of the HNCO molecule," Discussions of the Faraday Society, vol. 9, pp. 92-99, 1950.

[12] P. G. Maiella and T. B. Brill, "Spectroscopy of hydrothermal reactions," Applied Spectroscopy, vol. 50, pp. 829-835, 1996.

[13] J. Zhang, M. Lewin, E. Pearce, M. Zammarano, and J. W. Gilman, "Flame retarding polyamide 6 with melamine cyanurate and layered silicates," Polymers for Advanced Technologies, vol. 19, no. 7, pp. 928-936, 2008.

[14] P. Gijsman, R. Steenbakkers, C. Fürst, and J. Kersjes, “Differences in the flame retardant mechanism of melamine cyanurate in polyamide 6 and polyamide 66," Polymer Degradation and Stability, vol. 78, no. 2, pp. 219-224, 2002.

[15] Z. Y. Wu, W. Xu, Y. C. Liu, J. K. Xia, Q. X. Wu, and W. J. $\mathrm{Xu}$, "Preparation and characterization of flame-retardant melamine cyanurate/polyamide 6 nanocomposites by in situ polymerization," Journal of Applied Polymer Science, vol. 113, no. 4, pp. 2109-2116, 2009.

[16] R. Henricus and M. Kierkels, "Patent application title: Melamine cyanurate in crystalline form Inventors," JoAnn Villiamizar, Ciba Corporation/Patent Department, EP1799655A1, 2007.

[17] R. J. Meier, J. R. Maple, M. J. Hwang, and A. T. Hagler, "Molecular modeling urea- and melamine-formaldehyde resins. 1. A force field for urea and melamine," Journal of Physical Chemistry, vol. 99, no. 15, pp. 5445-5456, 1995.

[18] P. J. Larkin, M. P. Makowski, N. B. Colthup, and L. A. Flood, "Vibrational analysis of some important group frequencies of melamine derivatives containing methoxymethyl, and carbamate substituents: mechanical coupling of substituent vibrations with triazine ring modes," Vibrational Spectroscopy, vol. 17, no. 1-3, pp. 53-72, 1998.

[19] C. Y. Panicker, H. T. Varghese, A. John, D. Philip, and H. I. S. Nogueira, "Vibrational spectra of melamine diborate, $\mathrm{C}_{3} \mathrm{~N}_{6} \mathrm{H}_{6} 2 \mathrm{H}_{3} \mathrm{BO}_{3}$," Spectrochimica Acta A, vol. 58, no. 8, pp. 1545-1551, 2002.

[20] W. J. Jones and W. J. Orville-Thomas, “The infra-red spectrum and structure of dicyandiamide," Transactions of the Faraday Society, vol. 55, pp. 193-202, 1959.

[21] S. Debrus, M. K. Marchewka, M. Drozd, and H. Ratajczak, "Vibrational, calorimetric and nonlinear optical studies of melaminium-bis(trichloroacetate) monohydrate molecularionic crystal," Optical Materials, vol. 29, no. 8, pp. 1058-1062, 2007.

[22] E. García-López, G. Marci, N. Serpone, and H. Hidaka, "Photoassisted oxidation of the recalcitrant cyanuric acid substrate in aqueous $\mathrm{ZnO}$ suspensions," Journal of Physical Chemistry C, vol. 111, no. 49, pp. 18025-18032, 2007.

[23] A. Broido, "A simple, sensitive graphical method of treating thermogravimetric analysis data: part A-2," Journal of Polymer Science, vol. 7, no. 10, pp. 1761-1773, 1969.

[24] A. W. Coats and J. P. Redfern, "Kinetic parameters from thermogravimetric data," Nature, vol. 201, no. 4914, pp. 68-69, 1964.

[25] H. H. Horowitz and G. Metzger, "A new analysis of thermogravimetric traces," Analytical Chemistry, vol. 35, no. 10, pp. 14641468, 1963. 

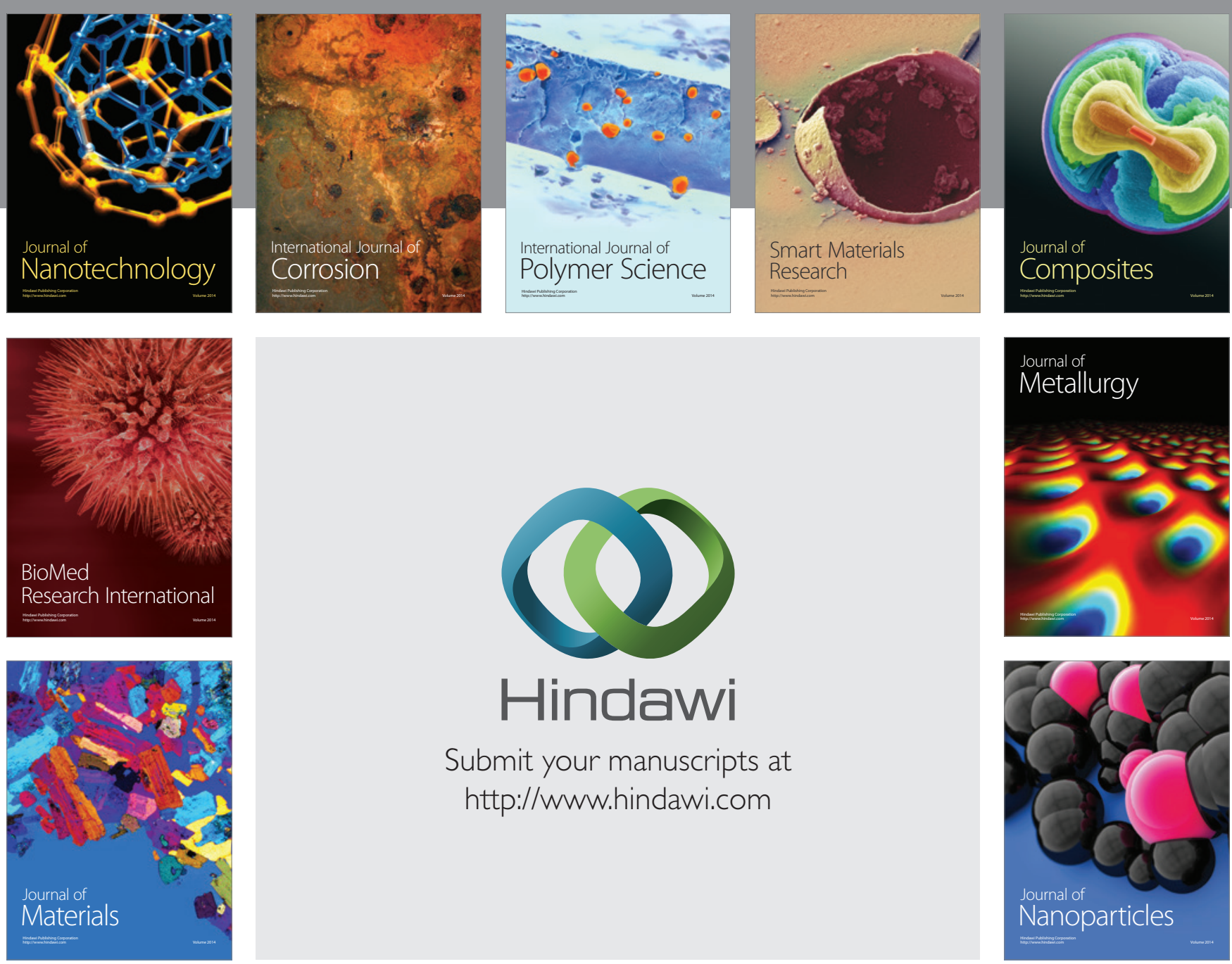

Submit your manuscripts at http://www.hindawi.com
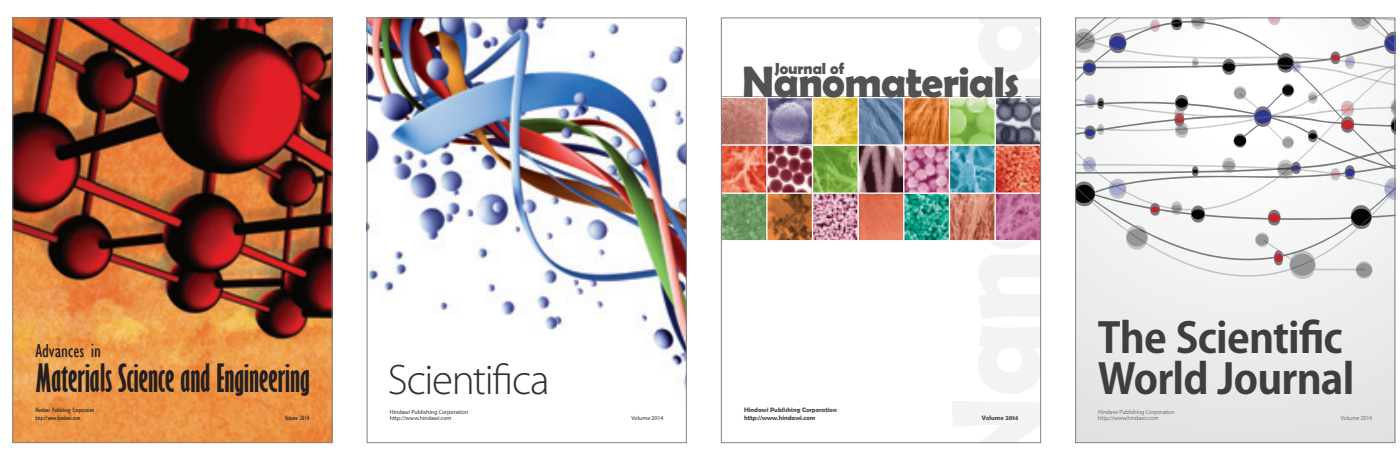

\section{The Scientific World Journal}
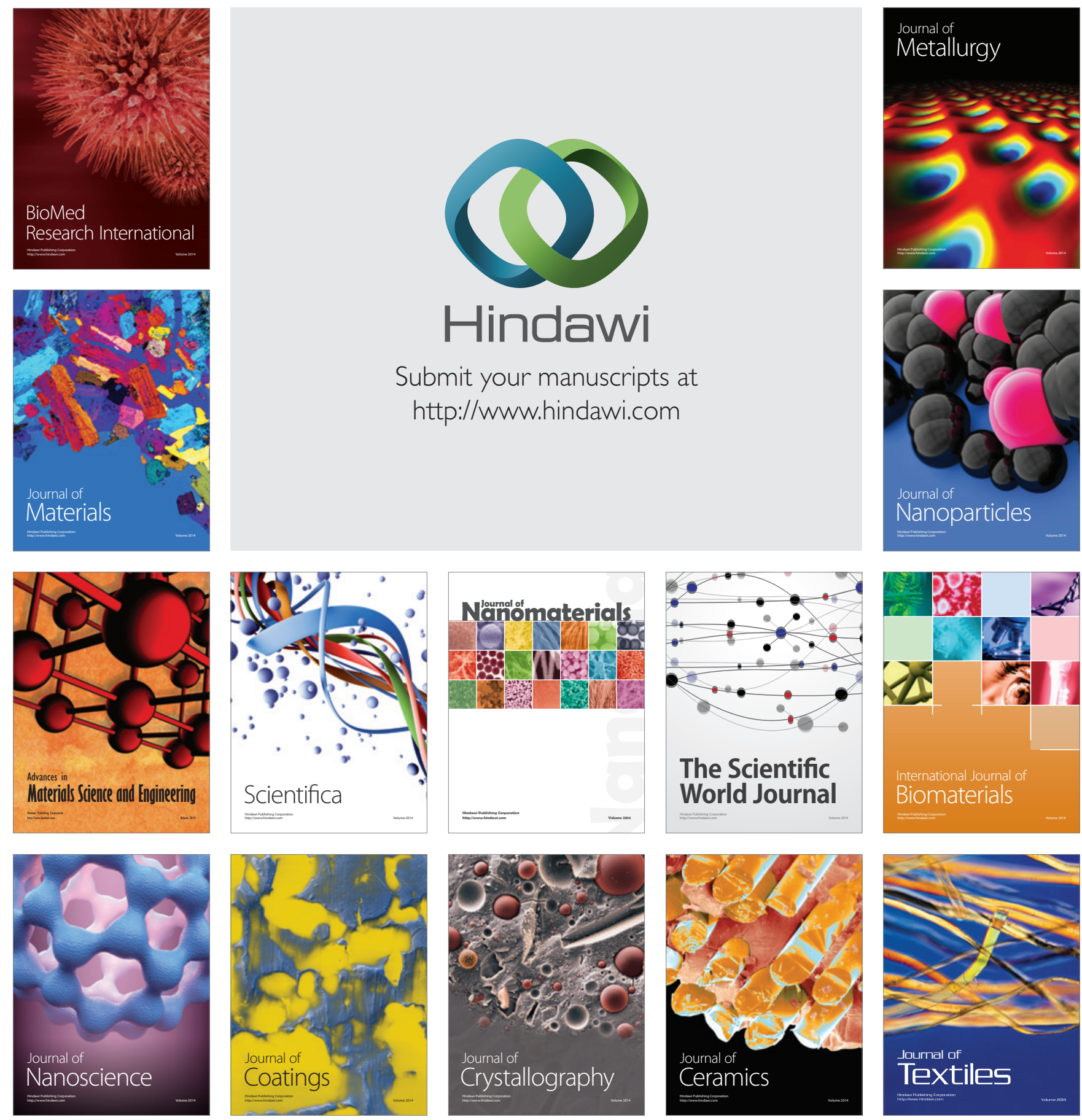